\title{
CONSTRUÇÃO E VALIDAÇÃO DE UMA ESCALA DE MEDIDA DE OPINIÃO-EMO SOBRE SAÚDE E DOENÇA MENTAL ${ }^{1}$
}

\author{
BUILDING AND VALIDATING AN OPINION MEASURING SCALE - OMS, ON \\ MENTAL HEALTH AND DISEASE \\ CONSTRUCCIÓN Y VALIDEZ DE UNA ESCALA DE MEDIDA DE OPINIÓN- \\ EMO SOBRE SALUD Y ENFERMEDAD MENTAL
}

Vera Lúcia Mendiondo Osinaga ${ }^{2}$
Antonia Regina Furegato

\begin{abstract}
RESUMO: Este estudo teve por objetivo a construção de um instrumento para se conhecer a opiniăo das pessoas sobre saúde e doença mental e sobre assistência, nesta área. Construimos e validamos uma Escala de Medida de Opinião - EMO, composta por 56 afirmativas sobre saúde, doença mental e assistência onde o sujeito demonstra seu grau de concordância, com o conteúdo expresso. As 5 etapas de construção do instrumento abrangem desde a formulação dos enunciados e respectivo aprimoramento do conteúdo das afirmativas, os testes de adequaçăo do conteúdo, de compreensăo e distribuição dos itens na Escala até os procedimentos de validação. $O$ instrumento definitivo foi aplicado junto a uma amostra de 250 sujeitos (portadores, familiares e profissionais). Os dados foram avaliados quantitivamente com provas não paramétricas e qualitativamente por comparação dos grupos, por categoria.
\end{abstract}

PALAVRAS CHAVE: opinião, saúde mental, enfermagem

INTRODUÇÃO

A história do fenômeno saúde e doença teve seu inicio nos primórdios da humanidade onde o homem se interrogava sobre este conceito e, com os recursos de cada época, procurava compreender, racionalizar, fazendo uso de sua inteligência e a capacidade de comparar e analisar. Os avanços da ciência permitiram comparar e tirar deduçōes e conclusōes e efetivar transformaçōes.

A busca do significado da doença remete necessariamente a uma interpretaçăo coletiva complexa e em constante movimento, ou seja, refere-se ao discurso da sociedade sobre as enfermidades e os enfermos. Para Spink (1993), "ao expormos nossas concepçōes de doença estamos falando, efetivamente, da sociedade e da nossa relaçăo com o mundo social".

As doenças, de um modo geral, suscitam diferentes reflexões pela possibilidade de uma nova interpretação do mundo que o cerca ou até mesmo pela sua negação.

Para Machado (1978), o século XIX marca historicamente o momento em que a loucura recebe status de doença mental. Até então, os loucos eram confundidos com outras vitimas das mazelas sociais e, quando confinados, isto ocorria em espaços indiscriminados, menos

\footnotetext{
'Prêmio Edith de Magalhaes Fraenkel, $1^{\circ}$ lugar, 51 CBEn

${ }^{2}$ Mestre pelo Programa de Pós Graduação em Enfermagem Psiquiátrica da EERP-USP.

${ }^{3}$ Prof. Titular do Depto. de Enfermagem Psiquiátrica e Ciências Humanas da EERP-USP.
} 
centrados na atençăo médica e voltados para o abrigo dos diversos desvalidos.

O hospital psiquiátrico surgiu com o tratamento moral e com o reconhecimento da especificidade da doença mental e da necessidade de separá-la das outras problemáticas, através da criação de um espaço terapêutico próprio. O espaço asilar foi concebido como um local ideal para a açăo terapêutica e planejado segundo uma série de dispositivos de funcionamento que garantissem esta açăo. Segundo esta concepçăo, năo havia tratamento sem hospital. Dentre estes dispositivos, o isolamento social era uma das principais condiçōes para a sua existência. Isto explica porque os hospitais eram construidos em locais periféricos de centros urbanos em formação (Machado, 1978).

O surgimento dos macro-hospitais nas periferias dos centros urbanos está relacionado com a emergência da medicina social e do movimento alienista.

Com o passar dos anos, ao tratamento moral acrescentou-se uma série de outras visões acerca da doença mental, como por exemplo, a psiquiatria organicista e as psicoterapias. Além disso, o tratamento asilar mostrou-se pouco eficaz, gerando, ao longo da sua existência, altos indices de reinternaçăo e grande número de pacientes crônicos. Para Machado(1978), objetivos terapêuticos propostos não foram alcançados e o espaço, inicialmente previsto para ser especifico dos loucos, assemelha-se ainda aos hospitais gerais da idade média: pois abriga todas as espécies de problemas sociais e os pacientes, na maioria das vezes, acham-se em situação de abandono.

Atualmente, esse modelo passa por grandes crises. Discutem-se inclusive a pertinência dos hospitais, seu referencial teórico e suas práticas, hoje consideradas coercitivas. Simultaneamente, com o intuito de se evitar novas internações e, com isto, conseguir a desativação dos asilos, tem havido um movimento de incentivo a outras formas de serviços de atenção em saúde e doença mental.

Entre esses serviços, destacamos o novo movimento de assistência ao doente mental, que tem exercido importante influência na criaçăo de uma cultura em muitos paises do mundo, a partir do entendimento de que o doente mental deve ser visto como cidadăo e năo apenas como objeto de intervenção psiquiátrica. Este movimento propõe a reestruturaçăo dos serviços de saúde mental, busca mobilizar diferentes setores da sociedade civil em torno dos direitos à cidadania dos portadores de transtornos mentais, assim como, denuncia atos de violência, discriminação e exclusăo que sofrem năo somente os "pacientes psiquiátricos", mas também aqueles que năo servem à estrutura do sistema capitalista de produçăo (Basaglia,1979).

Para Goffman (1974), institucionalização da loucura, a definiçăo das fronteiras da normalidade, a segregaçăo, a definiçăo de quem tem o poder de segregar, a perda da cidadania, da responsabilidade civil e o convivio com as diferenças voltam à tona com o questionamento da permanência e da pertinência dos asilos psiquiátricos atuais. Hoje percebe-se com maior clareza os preconceitos em relaçăo aos loucos e a visăo generalizada sobre sua periculosidade. Questiona-se a necessidade de confinamento e da perda da razăo como irreversivel e ameaçador para a segurança, para a ordem, e para a moral. Estes conceitos eståo sendo revisados e questionados.

A transformação dessa realidade passa năo somente pela discussăo de custos e destino das internações novas e dos já psiquiatrizados. Discute-se também a necessidade de romper o isolamento a que esses pacientes estăo submetidos, com a abertura dos hospitais e com sua reaproximaçăo com a comunidade. A nova visăo da assistência em psiquiatria requer discussões e trabalhos com as comunidades que rejeitaram os doentes e que agora deverăo recebé-los em seus espaços públicos e privados.

O conceito de doença mental foi mudando ao longo de sua história. O comportamento das diferentes sociedades, nas diversas épocas porque passou a humanidade, em face dos portadores destas lesర̋es, variou muito. Estes individuos, temidos ou rejeitados, até praticamente os nossos dias, são dificilmente aceitos e integrados à vida social. 
A concepção de doença mental, para Carvajal (1993), foi sofrendo mudanças ao longo da história, desde as culturas primitivas que a concebiam como um castigo do sobrenatural ou demoniaco e os bruxos e feiticeiros que tinham um papel fundamental na cura e recuperação do doente, na qual eram também partícipes os grupos sociais.

$\mathrm{Na}$ atualidade, Pessoti_(1995) acredita que a doença mental é uma transgressão das normas sociais, e portanto, ela não é nada mais que uma (des)ordem. Sendo "desordem" fere as normas sociais, năo é tolerada e por isso mesmo é reforçada a sua exclusão. $O$ individuo limitado pela doença perde a liberdade de escolha pessoal, encontra-se sem opção e preso a um só caminho.

Para este mesmo autor, ainda há na história uma intima relaçăo entre as diferentes concepçőes sobre doença mental e loucura e o contexto histórico no qual estão inseridas; há também muitas tentativas de se compreender e buscar explicaçőes sobre as doenças.

Ainda à luz desse tema, pensamos que a conceituação, a concepçăo e a assistência ao doente mental requerem uma volta ao sentido histórico e da sua evolução trazendo até a atualidade, quando assim nos deparamos com a realidade dessa nova forma de conceber $e$ compreender a doença, o doente e a assistência. Dentro dessa nova maneira de ver a doença se objetivam a reintegraçăo do doente mental na sociedade como cidadão, a retomada da vida familiar e produtiva, além da restituiçăo de seus direitos, tão lesados ao longo do tempo.

Vivenciando esta fase de grandes reflexōes sobre a concepção de saúde e doença mental, assim como, participando das intensas transformações na assistência nesta área, sentimos a premência de estudar o fenômeno sob a ótica de seus próprios atores.

\section{OBJETIVO}

Construir e validar um instrumento que possibilite conhecer a opinião de portadores de doença mental, seus familiares e profissionais desta área, sobre Saúde e Doença Mental e a Assistência.

\section{CONSTRUÇÃO E VALIDAÇÃO DA ESCALA DE MEDIDA DE OPINIÃO - EMO}

Ao nos decidirmos pela temática e os objetivos pretendidos nesta investigação, após várias leituras e reflexőes de publicações sobre metodologia cientifica, optamos pela construçăo de um instrumento que: 1 - fosse capaz de dar respostas à temática pesquisada, bem como manter um campo neutro entre o pesquisador e o pesquisado, diminuindo as possibilidades de interferência; 2 - que favorecesse uma apreensảo mais próxima do entendimento dos sujeitos sobre os conceitos e a assistência de Saúde/Doença Mental de forma confiável e o mais fidedigna possivel; 3 - que possibilitasse adotar uma abordagem quantitativa e qualitativa das informaçōes contidas nos dados.

Assim, decidimos pela construçăo e aplicaçăo de um instrumento tipo Escala. Vale ressaltar que, embora atenda às exigências de sua natureza psicológica, não pretendemos utilizá-la como teste psicológico. Adotamos os elementos estruturais necessários à confecçăo de um instrumento exclusivo para pesquisa, cujos passos de sua construçăo estăo minuciosamente descritos.

Motivadas pelo desenho teórico sobre o tema escolhido para o estudo e suas interrelações entre literatura, experiências e insights, iniciamos o percurso metodológico. As etapas da construção do instrumento estão explicitadas a seguir:

Primeira etapa - Montamos um conjunto de afirmativas procurando abranger o máximo possivel de elementos sobre o tema, tendo por base a literatura e a experiência de sermos enfermeiros psiquiátricos vivendo este momento de transformaçăo. Os enunciados foram sendo lapidados até chegarmos a uma Escala com 44 afirmativas. Cada afirmativa vem sempre 
acompanhada de cinco alternativas, através das quais esperávamos conhecer a visão dos sujeitos a respeito dos Conceitos sobre Saúde/Doença Mental e sobre a Assistência Psiquiátrica. Estas questões foram analisadas e reformuladas quanto à forma de apresentação e entendimento do respectivo conteúdo.

Segunda etapa - Após reformulado o instrumento, realizamos o primeiro estudo piloto, na própria instituiçăo onde foi desenvolvido um estudo com o objetivo de verificar a adequação do conteúdo do instrumento (Osinaga, 1999).

Este instrumento foi aplicado no Hospital Espírita e no Centro Comunitário de Saúde Mental, no início de 1998. A amostra com 10 sujeitos era composta por familiares, pacientes e profissionais da equipe daquele hospital. Foram escolhidos aleatoriamente, junto a uma população com caracteristicas semelhantes às da amostra definitiva. Este procedimento serviu também como teste de estabilidade do instrumento, visto ter sido reaplicado na mesma populaçăo, obedecendo o critério de exclusão deste grupo investigado.

Antes dessa atividade, entramos em contato com a direção das Instituições, afim de expor os objetivos do projeto e obter autorizaçăo para os procedimentos técnicos para os testes, coleta e a utilização dos dados.

Prosseguindo na articulação de aplicação do teste piloto, agendamos dia e hora para começar o trabalho e também para fazer contatos com os pacientes e os familiares nos dias de visitas.

Nas duas instituiçőes referidas, optamos fazer contato com os pacientes, no pátio. Esse recurso facilitou o acesso aos familiares, pois ao abordá-los muitos deles haviam sido informados pelos internos. No caso dos familiares procuramos năo comprometer a visitação dos seus internos, sendo aplicado o instrumento antes do horário de visitas, em ambientes reservados como os consultórios. No tocante a coleta dos profissionais foi realizado no local e horário de trabalho.

Escolhemos um de cada vez para conversar sobre os objetivos do trabalho. Todos mostraram-se solícitos e motivados por estarem participando da pesquisa.

Durante a aplicação deste piloto, percebemos certas dificuldades de compreensão dos participantes sobre determinadas afirmativas, bem como dúvidas, que poderiam prejudicar as respostas; estas foram consideradas contribuiçōes importantes que serviram para o reajuste do instrumento.

Terceira etapa - Realizamos a análise do instrumento aplicado, assim como das observaçőes feitas pela entrevistadora durante este procedimento. Foi revisada cada uma das afirmativas na sua forma de apresentação, na sua distribuição por temas e nas observaçōes realizadas durante o estudo piloto. Este cuidado visava a homogeneidade dos itens. Algumas questőes que estavam na forma negativa foram corrigidas para a forma afirmativa, assim como a subtraçăo dos vicios de linguagem para evitar confusão ou dupla interpretaçăo. As questões que se mostraram repetitivas foram eliminadas. A forma de apresentaçăo do titulo também foi mudada.

Após esta reorganização, o instrumento foi denominado ESCALA DE MEDIDA DE OPINIĀO-EMO.

Incluimos um texto de apresentação do instrumento explicando seus objetivos e o modo de responder ao teste, bem como a identificação das categorias dos respondentes, os agradecimentos pela colaboração e o compromisso do sigilo.

As respostas deste primeiro teste sofreram uma tabulação por questōes para que pudéssemos analisar as tendências por resposta. Analisando estes resultados, foi possivel ter uma idéia do impacto destas afirmativas. Algumas questőes foram reformuladas, reagrupadas ou desmembradas totalizando 60 afirmativas, no final desta etapa.

Quarta etapa - Este instrumento, após os ajustes mencionados, foi aplicado em uma segunda amostra de 8 sujeitos: pacientes, familiares e profissionais no NAPS - Núcleo de 
Apoio Psicossocial de Ribeirăo Preto, todos profissionais de assistência psiquiátrica, devidamente autorizados pela direçăo da Instituiçăo para a realizaçăo do teste, obedecidos os critérios adotados na primeira coleta.

A opção para a reaplicação do EMO obedeceu aos critérios de semelhança entre as instituiçőes e da população que a frequèenta.

Quinta etapa - Após a aplicação do instrumento no NAPS, o mesmo foi analisado por um grupo de juizes, doutorandos em enfermagem, a fim de verificar a adequação do conteúdo, a clareza de entendimento e a compreensão dos itens que iriam compor o material definitivo. Esta validaçăo foi realizada pelos integrantes do GERES - Grupo de Estudos das Representaçōes Sociais, que se reuniam naquele período.

Foram sugeridas modificações na apresentação: a página inicial permaneceria sem alteraçōes; foi incluida uma segunda página, com os dados de identificaçăo dos respondentes. As questőes foram analisadas e reformuladas, quanto à adequaçăo da abordagem e a clareza da linguagem, reduzindo-se a um total dé 56 afirmativas.

A montagem definitiva do instrumento contou ainda com uma ordem de apresentaçăo aleatória, baseada em sorteio de duplo cego.

Após todas as reformulações, testes, avaliaçōes e validação o processo de construção da EMO - ESCALA DE MEDIDA DE OPINIÃO pode ser considerado concluido (Anexo 1). Este instrumento pode ser aplicado e analisado conforme o modelo adotado.

\section{SOBRE ESCALAS DE MEDIDA E A EMO}

Segundo Pasquali (1998), para a elaboração de qualquer Escala Psicológica devemos seguir alguns princípios na construçăo dos testes psicológicos de aptidão. O modelo baseia-se em três procedimentos que são: os teóricos, os empiricos(experimentais) e os procedimentos analíticos(estatísticos). Os procedimentos téricos devem ser elaborados para cada instrumento, dependendo do assunto psicológico que vai ser investigado como instrumento que se pretende medir. O procedimento empírico ou experimental define as etapas e técnicas de aplicaçăo do instrumento, coleta de informaçōes para proceder a avaliação da qualidade psicométrica do instrumento.

Este mesmo autor salienta que, para a construçăo de qualquer tipo de escala a ser utilizada para medir é fundamental que se conheçam os conceitos de confiabilidade e validade. Segundo Armstrong, apud Menezes (1998), o termo confiabilidade é utilizado para referir-se ao grau de concordância entre múltiplas mensurações de um mesmo objeto.

Pasquali(1997) diz que a fidedignidade de um teste diz respeito à característica de medir sem erros. Por isso, recomenda-se confiabilidade e fidedignidade. Medir sem erros significa que o mesmo teste, medindo os mesmos sujeitos em ocasiões diferentes, ou testes equivalentes medindo os mesmos sujeitos na mesma ocasião, produzem resultados idênticos.

A EMO foi aplicada no Rio Grande do Sul, em duas instituiçőes, junto a portadores de doença mental, familiares e profissionais desses serviços (Osinaga, 1999). Estudos posteriores poderão confirmar a validade desse instrumento junto à mesma população estudada e outras elegiveis.

Menezes(1998) afirma que quando planejamos utilizar um instrumento em uma investigaçăo deve-se fundamentalmente realizar um estudo de confiabilidade. Este estudo servirá para o treinamento dos entrevistadores e para identificar problemas com o instrumento. Outro fator importante é a escolha das pessoas que participarăo do estudo de confiabilidade. Esses devem ser semelhantes à populaçăo que será investigada no estudo definitivo.

Este procedimento foi levado em consideração durante a construçăo da EMO, nos vários testes realizados.

O processo de validaçăo de um teste, para Anastasi (1986), inicia-se com a formulaçăo 
de definiçőes detalhadas do traço ou construto, derivadas da teoria psicológica, da pesquisa anterior ou da observaçăo sistemática e análises do domínio relevante do comportamento. Os itens do teste são então preparados para se adequarem às definiçōes do construto. Análises empiricas dos itens seguem, selecionando-se finalmente os itens mais eficazes da amostra inicial de itens.

O embasamento teórico sobre o tema sob investigaçăo faz parte do aprofundamento dos autores deste instrumento nos estudos sobre Saúde e Doença Mental assim como sobre a Assistência em Psiquiatria, ao longo da história e seus desdobramentos atuais.

A partir das conceituaçōes da construção, validação e fidedignidade de uma escala, vale ainda esclarecer alguns aspectos conceituais sobre a Escala, do tipo Likert (1932).

Rensis Likert (1932) criou uma escala de simples confecçăo e aplicação e que possui boa correlaçăo com outras escalas de critérios de medidas de atitude, dentre as quais esta talvez seja a mais utilizada na construçăo de escalas psicométricas.

Segundo Pasquali_(1996), esta escala se apresenta como o método dos pontos somados. Com base em Likert, sustenta que uma atitude constitui uma disposiçăo para a açăo. Considera atitude como um elemento da personalidade e igualmente defende que há uma série de construtos de personalidade e não apenas um único, isto é, as propriedades psicológicas têm magnitudes, e por isso é que podem ser medidas.

Existem várias definiçőes do que sejam atitudes. Apesar das divergências na sua definiçăo, Valla (1993) diz que o conceito de atitude talvez tenha sido o primeiro a dar identidade à psicologia social, posicionando-se como um elo de ligação entre a psicologia individual e a sociologia na medida em que permitia identificar o posicionamento de um indivíduo específico face à realidade social.

Autores como Bem (1973) definem atitudes como os gostos e as antipatias. Entendem que são as nossas afinidades e aversōes a situaçōes, objetos, grupos ou quaisquer outros aspectos identificáveis do meio, incluindo idéias abstratas e politicas sociais que definem as atitudes. Isto porque nossas emoçס̃es, nosso comportamento e as influências sociais são exercidas sobre as pessoas e consequentemente refletindo suas dimensões.

Vários estudos procuram mostrar a relaçăo entre opiniőes, crenças e atitudes, apresentando-as como logicamente ligadas, dentre os quais destacamos:

McGuire (1969) procurou fazer uma diferenciaçăo entre atitude e opiniăo sendo opinião entendida como uma entidade observável, enquanto que atitude pode ser inferida mas não diretamente observada. Por outro lado, pressupōe que tanto atitude como opiniăo têm ligaçăo com os comportamentos.

Bem_(1973) enfatiza que opiniões derivam de um conjunto comum de valores subjacentes. Relata ainda que, coletivamente, as crenças ou opiniőes de um homem formam a compreensão que tem de si mesmo e do seu meio sendo que muitas das opiniőes são produto da experiência direta.

Festinger citado por Radloff (1961) postulou que existe no organismo humano, um impulso interno para avaliar suas opiniões e habilidades. Na falta de critérios avaliativos objetivos, as opiniőes são comparadas com as de outras pessoas. As opiniőes podem ser entăo consideradas corretas ou incorretas em termos de concordância ou discordância com as opiniőes que os outros possuem sobre o mesmo objeto.

Em nosso estudo sobre opiniōes năo utilizamos a escala Likert para determinar o valor escalar dos itens, mas para verificar níveis de concordância dos sujeitos com uma série de afirmações que expressam algo de favorável ou desfavorável em relaçăo à concepção de Saúde e Doença Mental e sobre a Assistência, nessa área.

Na escala tipo Likert, ao registrar sua opinião a pessoa, não só concorda ou discorda de uma afirmaçăo, como também indica até que ponto concorda ou discorda em uma graduação que vai desde "concordo totalmente até discordo totalmente". Para Ragazzi (1976) a validação 
de uma escala do tipo Likert pode ser obtida pelos métodos de validaçăo concomitante ou simultânea ou também pelos de validaçăo de conteúdo. Estes indicam até que ponto os itens em uma escala representam o universo de crenças, sentimentos ou tendências das pessoas para a açăo, com relação a determinado objeto.

\title{
CONCLUSŐES
}

A EMO - ESCALA DE MEDIDA DE OPINIÃO foi aplicada junto a uma amostra de 250 sujeitos (100 portadores, 109 familias e 41 profissionais) em 2 serviços psiquiátricos no Rio Grande do Sul.

Os dados quantitativos foram analisados com provas não-paramétricas e os qualitativos através de comparaçōes entre as respostas que sobressairam nos três grupos nas duas categorias Conceito e Assistência em Saúde/Doença Mental.

Dessas análises, concluimos que os grupos nas duas categorias diferem tanto na categoria Conceito como na categoria Assistência; os portadores estăo mais concordantes com relaçăo às afirmações sobre os Conceitos seguidos dos familiares e dos profissionais. Sobre a Assistência houve maior concordância dos familiares, seguido dos portadores e dos profissionais.

O teste Wilcoxon permitiu concluir que os portadores e os profissionais tendem a concordar mais freqüentemente com relação ao Conceito de Saúde/Doença Mental do que com Assistência.

Os pesquisadores do NUPRI estăo iniciando outras pesquisas de opiniăo sobre saúde e doença mental e a assistência nesta área junto a outros grupos populacionais, utilizando o mesmo instrumento aqui apresentado, a EMO - ESCALA DE MEDIDA DE OPINIÃO.

Construimos um instrumento de pesquisa que poderá ser aplicado por outros estudiosos, assim como o procedimento utilizado neste processo poderá servir de modelo para a construção de outros instrumentos dessa natureza.

\begin{abstract}
The aim of this study was the construction of a tool in order to know people opinion about mental health, illness and care in this area. We constructed and validated a Scale of opinion measurement, formed by 56 affirmations about mental health, illness and care in which the subjects demonstrated their agreement to the expressed content. The 5 stages of the scale construction involve the formulation of the statements and respective improvement of the affirmations content, understanding and the distribution of items in the Scale before the validation procedure. The definitive tool was applied in a sample of 250 subjects (patients, family members and health professionals). Data were quantitatively analyzed with non parametric proves and qualitatively analyzed through comparisons among groups, by categories.
\end{abstract}

KEYWORDS: opinion, mental Health, Nursing

RESUMEN: Este estudio tiene por objetivo la construcción de un instrumento para saber que opinión tiene la gente sobre la salud y la enfermedad mental y sobre la asistencia en esa área. Hemos construido y hemos hecho válida una Escala de Medida de Opinión - EMO, que se compone de 56 afirmativas sobre salud, enfermedad mental y asistencia, donde el sujeto demuestra su grado de anuencia/concordancia con el contenido expresado en la misma. Las 5 etapas de construcción del instrumento comprehenden desde la formulación de los enunciados y respectivo aprimoramiento del contenido de las afirmativas/afirmaciones, los tests para la adecuación del contenido, de comprensión y distribución de los apartados de la Escala hasta los procedimientos para su validez. 
El instrumento definitivo fue aplicado junto a una muestra de 250 sujetos (portadores, familiares y profesionales). Los datos se evaluaron cuantitativamente, con pruebas no paramétricas y calitativamente mediante comparación de los grupos, por categoria.

PALABRAS CLAVE: opinión, Salud Mental, Enfermeria

\section{REFERÊNCIAS BIBLIOGRÁFICAS}

ANASTASI, A. Evolving concepts of test validation. Annual Review of Psychology, 37. p. $1-15,1986$.

BASAGLIA, F. A psiquiatria alternativa: contra o pessimismo da razão, o otimismo da prática. Săo Paulo, Brasil Debates, 1979. 158p.

BEM, J.D. Conviç̧ões, Atitudes e Assuntos Humanos. Trad. de Carolina M. Rossi. São Paulo: EPU, 1973. p.5- 44 .

CARVAJAL, C.A. EI paciente mental crônico. La familia y su integración a la sociedad. Revista de Psiquiatria Clínica, Santiago de Chile, n. 2, v. xxx, p.131-141, 1993.

MACHADO, R.; LOUREIRO, A.; LUZ, R.; MURICY, K. Danação da norma: medicina social e constituição de psiquiatria no Brasil. Rio de Janeiro: Graal, 1978. 559 p.

McGUIRRE, J.W. The nature of attitudes change. In: Lindzey, G. and Aronson, E. (eds.), The handbook of social psychology. Reading: Addison Wesley, 1969. p.136-314, v. 3.

MENEZES, P.R. Validade e confiabilidade das escalas de avaliação em psiquiatria. Revista Psiquiátrica Clínica, Brasilia, v. 25, n. 5, p. 214-216, 1998. Edição. Especial.

PASQUALI, L. Psicometria: teoria e aplicaçōes. Brasilia: Universitária, 1997. 289p.

(org.). Teoria e métodos de medida em ciências do comportamento. Brasilia: INEP, 1996. 432p.

Principios de elaboraçăo de escalas psicológicas. Revista Psiquiátrica Clínica, Brasilia, v. 25, n. 5, p. 206-213, 1998. Edição Especial.

PESSOTTI, I. A loucura e as épocas. Rio de Janeiro: Editora 34, 1995. 206p.

RADLOFF, R. Opinion evaluation and affiliation. Joumal of Abnormal and Social Psychology, v.62, n.3, 1961. p.578-585.

SPINK, M.J. O conhecimento no cotidiano: as representaçōes sociais na perspectiva da psicologia social. São Paulo: Brasiliense, 1993. 311p.

VALA, J.: MONTEIRO, M.B. Psicologia Social. Lisboa: Fundação Calouste Gulbenkian, 1993. 475 p. 


\section{ANEXO 1}

ESCALA DE MEDIDA DE OPINIÃO - E.M.O.

Leia atentamente uma das afirmativas abaixo e assinale $\operatorname{com} X$, a sua posiçăo

AFIRMATIVAS Concordo totalmente Concordo pouco Indiferente Discordo pouco Discordo totalmente

01 - Se o doente freqüenta um serviço de atendimento diário fica mais fácil para o familiar mantê-lo em casa.

02 - Qualquer pessoa pode trabalhar em hospital psiquiátrico, basta ter jeito.

03 - O doente mental è mais bem tratado no convivio com sua familia do que no hospital.

04 - A doença mental em uma pessoa, causa ansiedade nos outros membros da familia.

05 - Nervosismo é sinal de loucura.

06 - O alcoolismo è doença mental.

07 - Através do contato direto com a pessoa que sofre, o enfermeiro conhece as verdadeiras necessidades dessa pessoa.

08 - Internar uma pessoa em hospital psiquiátrico significa que a familia o rejeita.

09 - $O$ doente mental tem o direito de ter trabalho e familia, como qualquer cidadão

10 - O doente mental é agressivo.

11 - É necessário dar suporte à familia para que possa cuidar do doente mental.

12 - O movimento da Reforma Psiquiátrica Brasileira tem ampliado recursos extra hospitalares para assistência.

ESCALA DE MEDIDA DE OPINIÃO-E.M.O.

Leia atentamente uma das afirmativas abaixo e assinale $\operatorname{com} X$, a sua posiçăo

AFIRMATIVAS Concordo totalmente Concordo pouco Indiferente Discordo pouco

Discordo totalmente

13- O lugar do lucro é no hospicio, entre quatro paredes.

14 - Hoje, nós encontramos mais doentes mentais sendo tratados fora dos hospitais.

15 - Até algum tempo atrás, o familiar do doente ficava por fora dos tratamentos psiquiátricos.

16 - Conhecendo as necessidades da pessoa que sofre, fica mais fácil para o enfermeiro ajudá-lo.

17 - Nos primeiros sinais de alteração, se a pessoa tivesse atendimento adequado, muitos casos psiquiátricos seriam evitados.

18 - Depressão é doença mental.

19 - O melhor lugar para o doente é ficar com sua familia.

20 - As diretrizes politicas da saúde mental melhoram a qualidade da assistência nos hospitais psiquiátricos.

21 - O familiar do doente mental é elemento importante no tratamento do mesmo.

22 - O bom enfermeiro precisa ser forte.

23 - Cuidar do doente mental é uma tarefa sofrida.

24 - A familia é a maior responsável pela piora do paciente.

ESCALA DE MEDIDA DE OPINIÃO - E.M.O.

Leia atentamente uma das afirmativas abaixo e assinale $\operatorname{com} X$, a sua posiçăo

AFIRMATIVAS Concordo totalmente Concordo pouco Indiferente Discordo pouco

Discordo totalmente

25 - A única soluçăo para o problema do doente mental é a interaçăo em hospital psiquiátrico.

26 - Ouvindo a familia pode-se ajudá-lo a encontrar soluçōes para os seus problemas.

27 - Depois que o paciente psiquiátrico começa a tomar remédios, ele só via piorando. 
28 - Para ter certeza de que alguém é doente mental é preciso estar próximo dele.

29 - O principal modo do enfermeiro ajudar o doente mental é através das relaçōes interpessoais.

30 - Hoje a familia continua por fora dos tratamentos do paciente psiquiátrico.

31 - Se uma pessoa usa droga acaba ficando doente mental.

32 - Quando alguém é internado em hospital psiquiátrico fico preocupado com a possibilidade dele receber maus tratos.

33 - Estão acontecendo mudanças nos tratamentos dos doentes mentais ultimamente.

34 - O doente mental é um ser inútil.

35 - A internaçăo deveria ser facilitada para os casos de agressão ou descontrole.

36 - O hospital psiquiátrico deveria acolher os mendigos

ESCALA DE MEDIDA DE OPINIÃO-E.M.O.

Leia atentamente uma das afirmativas abaixo e assinale $\operatorname{com} \mathrm{X}$, a sua posição

AFIRMATIVAS Concordo totalmente Concordo pouco Indiferente Discordo pouco

Discordo totalmente

37 - Somente o psiquiatra pode ajudar a pessoa que apresenta problemas emocionais

38 - O projeto de lei de Paulo Delgado que acaba com os grandes hospitais psiquiátricos, precisa ser logo aprovado.

39 - Dentro do hospital psiquiátrico, a equipe terapêutica mudou seu modo de tratar o doente mental, tendo para com ele atitudes mais humanizadas.

40 - A convivência com o doente mental provoca na familia tensão e conflitos que geram doença ou outros desequilibrios.

41 - O doente mental está cada dia menos perigoso.

42 - A visita freqüente do familiar é importante no tratamento do doente mental.

43 - Fala-se muito em mudanças e transformaçōes, porèm não temos visto nada na prática. Tudo está no mesmo.

44 - Ficar no hospital durante o dia e dormir em casa todas as noites é a melhor maneira de tratar o doente mental.

45 - Nas internaçōes de antigamente, o paciente ficava impregnado, amarrado ou tomava eletrochoque.

46 - É dificil diferenciar um doente mental de uma pessoa normal.

47 - Qualquer pessoa pode vir a ser doente mental.

48 - Quando o paciente toma medicação corretamente ele nem parece que é um doente mental.

ESCALA DE MEDIDA DE OPINIÃO - E.M.O.

Leia atentamente uma das afirmativas abaixo e assinale $\operatorname{com} X$, a sua posição

AFIRMATIVAS Concordo totalmente Concordo pouco Indiferente Discordo pouco

Discordo totalmente

49 - Hoje ainda existem hospitais com prisões e quartos-fortes.

50 - Tenho acesso fácil ao serviço psiquiátrico.

51 - Se tivesse bom atendimento nos laboratórios ou nos postos de saúde, diminuiriam as necessidades de internação.

52 - O profissional, em qualquer especialidade, tem que saber tratar a pessoa que tem problemas psiquiátricos.

53 - A epilepsia é doença mental.

54 - Existe atendimento de emergência onde eu moro, evitando internação.

55 - O enfermeiro tem uma funçăo importante junto às familias do doente mental, tanto nos hospitais como na comunidade.

56 - Nem todo problema emocional precisa de ajuda psiquiátrica. 